\title{
Avaliação microbiológica de queijo tipo mussarela fatiado comercializado em supermercados do município de Ji-Paraná - Rondônia
}

\author{
Microbiological evaluation of sliced mozzarella cheese marketed in supermarkets in the \\ municipality of Ji-Paraná - Rondônia
}

\section{Alexandra Marcela Reginato ${ }^{1}$, Tiago Barcelos Valiatti $^{2}$, Fabiana de Oliveira Solla Sobral $^{3}$, Natália Faria Romão}

Resumo: Foram adquiridas 20 amostras de queijo tipo mussarela fatiado oriundas de 4 supermercados, sendo estas submetidas a quantificação de Coliformes totais, Staphylococcus coagulase positiva e verificação de presença ou ausência de Salmonella sp. Os resultados obtidos demonstraram que todas as amostras apresentaram contaminação por Coliformes totais, dando destaque para o supermercado 1 que apresentou altas contagens, que variaram entre $1,4 \times 10^{6}$ e $2,3 \times 10^{6}$, estando essas em desacordo com a legislação, que determina $1 \times 10^{4}$ como valor máximo permitido. Para as análises de Staphylococcus coagulase positiva e Salmonella sp não se detectou presença em nenhuma das amostras analisadas, estando assim de acordo com a legislação. Os resultados obtidos foram satisfatórios para os microrganismos Staphylococcus coagulase positiva e Salmonella $\mathrm{sp}$, enquanto que, para o grupo dos coliformes totais $25 \%$ não atenderam ao recomendado pela legislação.

Palavras - Chaves: Leite e devirados, Microrganismos, Qualidade Microbiológica.

Abstract: Twenty samples of sliced mozzarella cheese were obtained from four supermarkets, which were subjected to quantification of total coliforms, positive coagulase Staphylococcus and verification of the presence or absence of Salmonella sp. The results showed that all samples showed contamination by total Coliforms, highlighting supermarket 1 that presented high counts, ranging from $1.4 \times 10^{6}$ to $2.3 \times 10^{6}$, which are in disagreement with the legislation, which determines $1 \times 10^{4}$ as the maximum allowed value. For the analyzes of Staphylococcus coagulase positive and Salmonella sp, no presence was detected in any of the analyzed samples, being thus in agreement with the legislation. The results obtained were satisfactory for the microorganisms Staphylococcus coagulase positive and Salmonella sp, whereas for the group of total coliforms $25 \%$ did not meet the recommended by the legislation.

Keywords: Milk and dairy products, Microorganisms, Microbiological quality.

Autor para correspondência: E. Mail: tiago_valiatti@hotmail.com

Recebido em 10.02.2019. Aceito em 30.03.2019

http://dx.doi.org/10.5935/1981-2965.20190006

1 Bióloga graduada pelo Departamento de Ciências Biológicas, Centro Universitário

Luterano de Ji - Paraná, Rondônia, Brasil - E-mail: nataliaromao2@gmail.com

${ }^{2}$ Farmacêutico graduado pelo Departamento de Farmácia, Centro Universitário Luterano de Ji

- Paraná, Rondônia, Brasil - E-mail: tiago_valiatti@hotmail.com 
${ }^{3}$ Biomédica, Docente do Departamento de Biomedicina, Centro Universitário Luterano de Ji - Paraná - Ji - Paraná, Rondônia, Brasil - E-mail: f.sobralbiomedica@gmail.com

4 Bióloga, Docente do Departamento de Ciências Biológicas, Centro Universitário Luterano de Ji - Paraná - Ji - Paraná, Rondônia, Brasil - E-mail: nataliaromao2@gmail.com

\section{Introdução}

O queijo é um dos alimentos mais consumido em todo o mundo, e apresentam diversos tipos, dentre eles o mussarela, que é comumente consumido pela população brasileira. Por ser um derivado do leite o queijo apresenta alta composição nutricional o que favorece a proliferação bacteriana indesejada.

Segundo o Ministério da Agricultura, Pecuária e Abastecimento, o queijo é definido como: “Um produto fresco ou maturado obtido por separação parcial do soro do leite ou leite reconstituído, ou de soros lácteos coagulados pela ação física do coalho, de enzimas específicas, de bactérias específicas, de ácidos orgânicos, isolados ou combinados, todos sendo de qualidade aceitável para o uso alimentar, com ou sem adição de substâncias alimentícias ou condimentos, aditivos"' (Brasil, 1996).

Dentre as diversas variedades de queijos, o mussarela é o tipo mais produzido Brasil, pois seu consumo é amplamente difundido, principalmente na culinária, devido suas propriedades de fatiamento e derretimento fácil. (LIMA FILHO \& POMBO, 2010; COELHO et al., 2012). A produção desse tipo de queijo engloba vários processos, sendo eles: pasteurização do leite, coagulação, corte do coágulo, dessoragem, enformagem, salga,

maturação e embalagem, e no caso do queijo tipo mussarela, ainda se inclui a fase de filagem (CONTIJO \& BRANCO, 1998).

Assim como o leite, o queijo também apresenta alto teor nutricional que favorece a viabilidade e/ou multiplicação de microrganismos que podem

comprometer a qualidade do produto, através de modificações nas suas características organolépticas, bem como causar surtos de Doenças Transmitidas por Alimentos (DTAs) (PIETROWSKI et al., 2008).

De acordo com Fagnani et al. (2013) e Pinto et al. (2009) apesar da produção do queijo do tipo mussarela incluir etapas que contribuem para redução da carga microbiana (Pasteurização e Filagem), posteriormente, o mesmo sofre intensa manipulação até a etapa final de produção, que se não for realizada mediante boas práticas de fabricação e higiene favorece a sua contaminação.

Dentre os principais microrganismos contaminantes frequentemente encontrados, destacamos os coliformes totais, Staphylococcus 
aureus e Salmonella spp. Os coliformes totais compreendem bactérias ambientais que são amplamente conhecidas por indicar as condições higiênico-sanitárias em que o alimento foi produzido. Sua presença em queijos do tipo mussarela pode indicar que a pasteurização empregada no processo foi ineficaz, já que esses microrganismos são sensíveis a temperatura utilizada na pasteurização, ou que o houve contaminação após essa etapa, possivelmente relacionada a manipulação inadequada (BELOTI, 2015; OLIVEIRA et al., 2017).

A bactéria $S$. aureus apresenta importante papel no cenário nacional dos surtos de DTAs, podendo essa provocar infecções ou intoxicações alimentares nos consumidores, ainda, sua presença nos alimentos sugerem possíveis falhas de manipulação, já que esse microrganismo é encontrado nas mucosas e pelo de humanos (BRASIL, 2018; FONSECA et al., 2010; FRANCO \& LANDGRAF, 2008).

Já a Salmonella spp. é o principal agente dos surtos de DTAs registados no mundo, e quando registrada sua presença no alimento, todo o lote deve ser desconsiderado para consumo. Manipulação inadequada, temperatura de manutenção incorreta e contaminação cruzada são fatores que propiciam a contaminação dos alimentos por essa espécie (FRANCO \& LANDGRAF, 2008).

$$
\text { O presente estudo teve como }
$$
objetivo avaliar a qualidade microbiológica do queijo tipo mussarela fatiado comercializado no município de $\mathrm{Ji}$ Paraná, por meio da contagem de coliformes totais, Staphylococcus coagulase positiva e presença/ausência de Salmonella sp.

\section{Material e métodos}

\section{Local}

Foram coletadas 20 amostras de queijo tipo mussarela provenientes de 4 supermercados do município de Ji Paraná, RO, que após adquiridas foram transportadas em caixas isotérmicas até o laboratório de microbiologia do Centro Universitário Luterano de Ji - Paraná (CEULJI/ULBRA).

\section{Procedimentos para análises microbiológicas}

Cada amostra foi pesada assepticamente $(25 \mathrm{~g}$ da amostra $)$ e realizada a diluição seriadas em água peptonada $0,1 \%$, correspondendo a $10^{-1}$, $10^{-2}, 10^{-3}, 10^{-4}, 10^{-5}$ e $10^{-6}$.

Para a análise de Coliformes totais, as diluições foram inoculadas $(1 \mathrm{~mL}) \mathrm{em}$ placas de petrifilm E.coli Count Plate AOAC Official Methods 991.14 e 998.08 conforme Silva et al. (2010) por plaqueamento direto, sendo estas em 
seguida incubadas em estufa à $35 \pm 1^{\circ} \mathrm{C}$ por 24 horas, onde após o período de incubação realizou-se a contagem das unidades formadoras de colônias (UFC) conforme instruções do fabricante.

Para a análise de Staphylococcus coagulase positiva, inoculou-se $0,1 \mathrm{~mL}$ das diluições em placas de petri contendo Ágar Baird-Parker (BP) - método da American Public Health Association (APHA) conforme Silva et al. (2010). Após inoculação as placas foram incubadas em estufa a $35 \pm 2^{\circ} \mathrm{C}$ por 48 horas, sendo posteriormente realizada a análise das colônias características e realização das provas bioquímicas para confirmação.

Para análise de Salmonella sp, $25 \mathrm{~g}$ da amostra foi pré-enriquecida com 225 $\mathrm{mL}$ de Água peptonada tamponada (BPW) e incubada à $37 \pm 1^{\circ} \mathrm{C}$ por $18 \pm 2 \mathrm{~h}$. Após a incubação, transferiu-se $0,1 \mathrm{~mL}$ da amostra para um tubo contendo Caldo Rappaport Vassiliadis e $1 \mathrm{~mL}$ para um tubo contendo caldo Tetrationato, sendo estes incubados à temperatura de $37^{\circ} \mathrm{C}$ por 24 horas, onde, posteriormente a esse período, realizou-se plaqueamento seletivo-diferencial em placas contendo Ágar Salmonella-Shigella (SS) e Ágar Verde Brilhante (BGA), por estriamento descontínuo. Após incubação a $35 \pm 2^{\circ} \mathrm{C}$ por $24 \mathrm{~h}$, verificou-se o aparecimento de colônias típicas e procedeu-se os testes bioquímicos utilizando kit BioMérieux Api 20E (SILVA et al., 2010).

\section{Delineamento experimental}

Os resultados foram analisados estatisticamente e expressos em unidades formadoras de colônias (UFC/g) e em presença ou ausência.

\section{Resultados e discussão}

A Tabela 1 apresenta a Contagem de Coliformes totais (UFC/g), Staphylococcus coagulase positiva (UFC/g) e verificação de Salmonella sp em amostras de queijo mussarela fatiado comercializados em supermercados do município de Ji-Paraná-RO. Segundo a Resolução-RDC No 12, de 02 de janeiro de 2001 (Brasil, 2001) a mesma não estabelece valores para o grupo dos coliformes totais, deste modo, utilizamos como referência a Portaria n. 146/96 (Brasil, 1996) que considera queijos mussarela impróprios para consumo aqueles que apresentarem contagens de coliformes totais acima de $1,0 \times 10^{4}$ $\mathrm{UFC} / \mathrm{g}$.

Portanto, ao levar em consideração os valores estabelecidos pela legislação para coliformes totais, $25 \%$ das amostras apresentaram contagens insatisfatórias, contudo, vale resultar que essas amostras eram todas correspondente ao 
supermercado 1 .

Ainda, as amostras provenientes do supermercado 4 foram as que exibiram menor contagem. Ainda de acordo com a
Tabela 1, verifica-se que todas as amostras estavam dentro dos padrões estabelecidos pela legislação vigente para Staphylococcus coagulase positiva que é de $1 \times 10^{3}$ (BRASIL, 2001).

Tabela1. Contagem de Coliformes totais (UFC/g), Staphylococcus coagulase positiva (UFC/g) e verificação de Salmonella sp em amostras de queijo mussarela fatiado comercializados em supermercados do município de Ji-Paraná-RO.

\begin{tabular}{|c|c|c|c|c|}
\hline \multirow[t]{2}{*}{ Supermercado } & \multirow[t]{2}{*}{ Amostra } & \multicolumn{3}{|c|}{ Microrganismos } \\
\hline & & $\begin{array}{l}\text { Coliformes } \\
\text { totais }\end{array}$ & $\begin{array}{c}\text { Staphylococcus } \\
\text { coagulase positiva }\end{array}$ & Salmonella $\mathrm{sp}$ \\
\hline \multirow{5}{*}{1} & 1 & $2,0 \times 10^{6}$ & $<1,0 \times 10^{1}$ & Ausente \\
\hline & 2 & $1,4 \times 10^{6}$ & $<1,0 \times 10^{1}$ & Ausente \\
\hline & 3 & $1,8 \times 10^{6}$ & $<1,0 \times 10^{1}$ & Ausente \\
\hline & 4 & $1,7 \times 10^{5}$ & $<1,0 \times 10^{1}$ & Ausente \\
\hline & 5 & $2,3 \times 10^{6}$ & $<1,0 \times 10^{1}$ & Ausente \\
\hline \multirow{5}{*}{2} & 1 & $6,0 \times 10^{1}$ & $<1,0 \times 10^{1}$ & Ausente \\
\hline & 2 & $4,0 \times 10^{1}$ & $<1,0 \times 10^{1}$ & Ausente \\
\hline & 3 & $3,0 \times 10^{1}$ & $<1,0 \times 10^{1}$ & Ausente \\
\hline & 4 & $1,0 \times 10^{2}$ & $<1,0 \times 10^{1}$ & Ausente \\
\hline & 5 & $5,0 \times 10^{1}$ & $<1,0 \times 10^{1}$ & Ausente \\
\hline \multirow{5}{*}{3} & 1 & $2,5 \times 10^{2}$ & $<1,0 \times 10^{1}$ & Ausente \\
\hline & 2 & $1,1 \times 10^{2}$ & $<1,0 \times 10^{1}$ & Ausente \\
\hline & 3 & $1,3 \times 10^{2}$ & $<1,0 \times 10^{1}$ & Ausente \\
\hline & 4 & $1,2 \times 10^{2}$ & $<1,0 \times 10^{1}$ & Ausente \\
\hline & 5 & $1,1 \times 10^{2}$ & $<1,0 \times 10^{1}$ & Ausente \\
\hline \multirow{5}{*}{4} & 1 & $1,3 \times 10^{2}$ & $<1,0 \times 10^{1}$ & Ausente \\
\hline & 2 & $2,0 \times 10^{1}$ & $<1,0 \times 10^{1}$ & Ausente \\
\hline & 3 & $7,0 \times 10^{1}$ & $<1,0 \times 10^{1}$ & Ausente \\
\hline & 4 & $<1,0 \times 10^{1}$ & $<1,0 \times 10^{1}$ & Ausente \\
\hline & 5 & $<1,0 \times 10^{1}$ & $<1,0 \times 10^{1}$ & Ausente \\
\hline
\end{tabular}


Oliveira et al. (2017) trabalhando com queijos mussarela oriundos do norte do Paraná apresentou 100\% das amostras dentro dos padrões estabelecidos para coliformes totais. Raimam (2011) que analisou amostras provenientes do sudoeste do Paraná, demonstrando que ambas as pesquisas foram em desencontro dos resultados observado nesse estudo.

Roges et al. (2017) ao analisar queijos mussarela de Jataí - GO verificou resultados semelhantes ao do presente estudo, pois observaram $20 \%$ das amostras com contagens de coliformes totais insatisfatórias.

Estudo realizado por Oliveira et al. (2017) com queijos mussarela oriundos do norte do Paraná apresentou 100\% das amostras dentro dos padrões estabelecidos para coliformes totais.

Além da pasteurização, os queijos mussarela são submetidos ao processo de filagem que é realizado utilizando água em temperatura de aproximadamente $80^{\circ} \mathrm{C}$, que consequentemente reduz totalmente a contaminação por coliformes totais visto que essas bactérias não sobrevivem a altas temperaturas, portanto, as altas contagens observadas nas amostras do supermercado 1 são provenientes de contaminação ocorrida em etapas seguintes do processamento, como desenformagem, salga, secagem, embalagem e transporte (FAGNANI et al.,
2013; BUZI et al., 2009).

Ainda, as amostras utilizadas nesse estudo foram submetidas ao procedimento de fatiamento que também favorece a contaminação, uma vez que ao fatiar alguma amostra já contaminada se não for realizada a limpeza adequada do fatiador às amostras seguintes irão se contaminar, conforme demonstrado experimentalmente por Faria (2016) utilizando amostras de carne contaminadas por Listeria monocytogenes.Marinheiro et al. (2015) no município de Pelotas, RS, ao analisar 20 amostras de queijo mussarela fatiado constataram que $20 \%$ estavam em desacordo com a legislação, pois apresentaram contaminação por Staphylococcus coagulase positiva acima de $1 \times 10^{3}$, entretanto, ao analisarem 20 amostras em peça inteira observaram que todas estavam de acordo com o estabelecido pela lei, sugerindo portanto, que a etapa de fatiamento foi responsável pela contaminação das amostras. Já Quintana e Carneiro (2007) ao analisar queijo tipo Mussarela e Minas Frescal, da cidade de Morrinhos em Goiás evidenciou que $100 \%$ das amostras do tipo mussarela se encontraram dentro dos padrões exigidos para Staphylococcus coagulase positiva, bem como Santos-Koell, Mattana e Hermes (2009) ao analisar amostras da região Oeste do Paraná, sendo esses 
resultados idênticos aos aqui encontrados.

Resultados dentro da legislação para Staphylococcus coagulase positiva são importantes, uma vez que esse microrganismo possui capacidade de produzir enterotoxinas que quando ingeridas podem desencadear um quadro de intoxicação, que geralmente é acompanhado de sintomas que inclui náuseas, vômitos, cólicas e diarreia (WONG \& BERGDOLL, 2002; GERMANO E GERMANO, 2003).

A atual legislação brasileira determina ausência de Salmonella sp, em 25 gramas de queijo mussarela (Brasil, 2001), sendo assim, conforme exposto na Tabela 1, os resultados encontrados no presente estudo para este microrganismo apresentaram dentro dos parâmetros estabelecidos, já que não foi detectado sua presença em nenhuma das amostras.

Estudos como o de Rodrigues et al., (2011), Silva et al. (2013) e Santos-Koell, Mattana e Hermes (2009) apresentaram resultados idênticos ao do presente estudo, ou seja, ausência de Salmonella sp. em $100 \%$ das amostras.

Contudo, estudo desenvolvido por Marinheiro et al. (2015) constatou que 5\% das amostras de queijo mussarela fatiado estavam contaminadas por Salmonella sp. Já Castro et al. (2012) constataram que do total de amostras de queijo do tipo mussarela analisadas, 33,33\% apresentaram positividade para Salmonella sp. enquanto que, o percentual de contaminação verificado no estudo de Roges et al., (2017) foi de $20 \%$.

4. Conclusão

De acordo com os resultados apresentados, todas as amostras de queijo tipo mussarela fatiado analisadas estavam dentro dos padrões vigentes na legislação para os microrganismos Staphylococcus coagulase positiva e Salmonella sp. Porém vale ressaltar que as amostras do supermercado 1 apresentaram altas contagens de coliformes totais, estando acima do limite recomendado pela legislação, indicando que houve falha durante seu processamento.

\section{Referências}

1.BELOTI, V. Leite: Obtenção, inspeção e qualidade. Londrina: Editora Planta, 2015a. $420 \mathrm{p}$.

2.BRASIl. Agência Nacional de Vigilância Nacional. RDC n. ${ }^{\circ} 12$ de 2 de janeiro de 2001. Regulamento técnico sobre padrões microbiológicos para alimentos. Diário Oficial da União, Brasília, 2001.

3.BRASIL. Ministério da Agricultura, Pecuária e Abastecimento. Aprova os regulamentos técnicos de Identidade e Qualidade dos produtos lácteos. Portaria $\mathrm{n}^{\mathbf{0}} 146$ de 07 de março de 1996. Diário Oficial da União, Brasília, 1996. Seção 1, p. 39-77.

4. BRASIL. Ministério da Saúde. Surtos de Doenças Transmitidas por Alimentos no Brasil. Dados epidemiológicos. Brasília, 2018. Disponível em: http://portalarquivos2.saude.gov.br/images/pdf /2018/julho/02/Apresentacao-Surtos-DTA- 
Junho-2018.pdf. Acessado em: 25 de dez de 2018.

5. BUZI, K.A.;PINTO J.P.A.N.;RAMOS, P.R.R.; BIONDI, G.F. Análise microbiológica e caracterização eletroforética do queijo mussarela elaborado a partir de leite de búfala. Ciência e Tecnologia de Alimentos. v. 29, n. 1, p. 7-11, 2009.

6. CASTRO, A.C.S.; PINTO, W.R.;TAPIA, D.M.T.;CARDOSO, L.G.. Qualidade de queijos do tipo Mussarela. Alimentos e Nutrição. v. 23, n. 3, p. 407-413, 2012.

7. COELHO, K.O.;MESQUITA, A.J., MACHADO, P.F.;OLIVEIRA, A.N.;SOUZA, C.M.;MEYER, P.M. Níveis de células somáticas sobre a proteólise do queijo Mussarela. Revista Brasileira de Saúde e Produção Animal. v. 13, n. 3, p. 682-693, 2012.

8. FAGNANI, R. et al. Pontos de contaminação microbiológica em indústrias de queijo mussarela. Revista Brasileira de Medicina Veterinária. v. 35, n. 3, p. 217-223, 2013.

9. FARIA, D.B. Contaminação cruzada durante o fatiamento de produto cárneo pronto para o consumo: foco em Listeria monocytogenes. Dissertação (Mestrado) Faculdade de Ciências Farmacêuticas. Universidade de São Paulo, São Paulo, 2016.

10. FONSECA, S.F. et al. (2010). Qualidade microbiológica de queijo Tipo Mussarela ralado comercializado a granel. En: CIC, 18, ENPOS, 11, Amostra científica, Congresso levado a cabo em la Universidade Federal de Pelotas/UFPel.

11. FRANCO, B.D.G.M.;LANDGRAF, M. Microbiologia dos alimentos. São Paulo: Atheneu. 2008.

12. GERMANO, P.M.L.;GERMANO, M.I.S. Agentes bacterianos de toxinfecções. In: Higiene e vigilância sanitária de alimentos. São Paulo: Varela, 2003, p.215-275.

13. GONTIJO, C.M.,BRANCO, A.B.A, Avaliação microbiológica do leite pasteurizado e de derivados do leite no Distrito Federal, janeiro/1990 a dezembro 1996. Revista de Saúde do Distrito Federal. v.9, n.2, p.2732,1998.

14. LIMA FILHO, R.R..;POMBO, G. Aumenta o consumo de queijo no Brasil. Carta Leite, 2010. Disponível em: <http://www.bovinos.ufpr.br/100921_Aumenta _o_consumo_de_queijo_no_brasil_def.pdp>.

Acesso em: 28 de nov. de 2018.

15. MARINHEIRO, M.F.;GHIZZI, L.G.; CERESER, N.D.;LIMA, H.G.;TIMM, C.D. Qualidade microbiológica de queijo mussarela em peça e fatiado. Semina: Ciências Agrárias. v.36, n.3, p.1329-1334, 2015.

16. OLIVEIRA, A.M.;KURIHARA R.Y.; SILVA, F.F.;SILVA F.G.;RIBEIRO- JÚNIOR, J.C.;BELOTI, V. Condições higiênicosanitárias da produção de queijos tipo mussarela e minas frescal comercializados no norte do Paraná. Revista do instituto de laticínios Cândido Tostes. v.72, n.1, p.40-47, 2017.

17. PIETROWSKI, G.A.M.; RANTHUM, M.; CROZETA, T.; JONGE, V. Avaliação da qualidade microbiológica de queijo tipo Mussarela comercializado na cidade de Ponta Grossa, Paraná. Revista Brasileira de Tecnologia Agroindustrial, Ponta Grossa, v. 2, n. 2, p. 25-31, 2008.

18. PINTO, M.S.;FERREIRA, L.L.F.; MARTINS, J.M.;TEODORO, V.A.M.; PIRES, A.C.S.; FONTES, L.B.A.; VARGAS, P.B.A. Segurança alimentar do queijo minas artesanal do Serro, Minas Gerais, em função da adoção de boas práticas de fabricação. Revista Pesquisa Agropecuária Tropical, v. 39, n. 4, p. 342-347, 2009.

19. QUINTANA, R.C.;CARNEIRO, L.C. Avaliação das condições higiênico-sanitárias dos queijos minas frescal e mussarela produzidos na cidade de Morrinhos - GO. Revista Brasileira de Saúde e Produção Animal. v. 8, n.3, p. 205-211, 2007.

20. RAIMANN, V.I. Avaliação microbiológica de queijos mussarela produzidos na região sudoeste do Paraná. Monografia (Especialização) - Universidade Federal do Paraná, Curitiba, 2011. 
21. REGES, J.;BORGES, A.;DA SILVA, J.; MOREIRA DOS SANTOS, S.;DE ALMEIDA COSTA MAIA, A.;VIEIRA, W.; NOGUEIRA DE JESUS, M.; DUARTE, S. Qualidade microbiológica e físico química do queijo mussarela a granel comercializadas em Jataí (Goiás, Brasil). Revista Colombiana de Investigaciones Agroindustriales. v.4, n.1, p.69-77, 2017.

22. RODRIGUES, J.;FARIAS, H.L.F.; BARBOSA， B.F.F.;GARCIA， T.A.;ISSY, P.N.; ARMONDES, M.P.O. Levantamento das características físico-químicas e microbiológicas de queijo minas frescal e mussarela produzidos no entorno de Goiânia GO. Revista da Universidade Vale do Rio Verde, Três Corações, v. 9, n. 1, p. 30-34, 2011.

23. SANTOS-KOELL, F.T.; MATTANA, A.; HERMES, E. Avaliação microbiológica do queijo tipo mussarela e queijo colonial comercializado na região oeste do Paraná. Revista Brasileira de Tecnologia Agroindustrial. v. 3, n. 2, p. 66-74, 2009.

24. SILVA, F.S.; NUNES, E.R.C.; SANTOS, J.F.; DUTRA， B.F.;LIMA， C.S.O.;LIMA, M.A.L.;LIMA, P.R.B.;ALMEIDA, E. Qualidade microbiológica do queijo tipo mussarela produzido e comercializado sob inspeção estadual na microrregião de Garanhuns, Pernambuco. XII Congresso Internacional do Leite. Embrapa. Porto Velho, 2013.

25. SILVA, N. et al. Manual de métodos de análises microbiológicas de alimentos e água. 4.Ed. São Paulo: Livraria Varela, 2010.

26. WONG, A.C.L.;BERGDOLL, M.S. Staphylococcal food poisoning. In: CLIVER, DO; RIEMANN, H.P. Foodborne Diseases. 2.ed. Amsterdam: Academic Press, 2002. p.231-248. 